\title{
Pertanggungjawaban Pidana Pelaku Kejahatan Pembobolan Kartu ATM Melalui Skimming
}

\author{
Criminal Accountability of Perpetrators of Crime of ATM Card Burglary \\ Through Skimming
}

\author{
Mohamad Arsan Abidin \\ Wiraswasta \\ E-mail: mohamad.arsan.2017@gmail.com \\ Sabrina Hidayat \\ Pascasarjana Universitas Halu Oleo \\ E-mail: sabrina.hidayat54@yahoo.com \\ Handrawan \\ Pascasarjana Universitas Halu Oleo \\ E-mail: handrawansaranani84@gmail.com
}

\begin{abstract}
The purpose of this study is for actions that can be taken to prevent the crime of breaking into ATM cards through skimming and to analyze the accountability for crimes of breaking into ATM cards through skimming. This study uses several approaches, namely the statute approach, the case approach, and the conceptual approach (conceptual approach) with legal base materials and secondary with prescriptive techniques. Based on the results of the study that 1) the actions that can be taken to prevent the crime of breaking into ATM cards through Skimming are building anti-malware prevention/defense on all bank servers, network security, protecting the network from attacks, monitoring and controlling tests, creating applications to report any cybercrime incidents, especially regarding skimming and increasing cooperation between countries in efforts to handle cybercrime, especially skimming. 2) Criminal liability for ATM card burglary through skimming is based on the fulfillment of the elements of offense and criminal threats against the perpetrators of the crime of skimming may be subject to Article 30, Article 46, Article 32, Article 48 of the ITE Law considering the principle of lex specialis derogate legi generali. However, in its application it cannot be applied alone to take action against skimming perpetrators, so it must be applied simultaneously with criminal law, namely Article 362 of the Criminal Code, Article 363 paragraph (1) of the 4th in conjunction with Article 263 in conjunction with Article 55 paragraph (1) of the 1st Criminal Code (inclusion of ). In addition, the crime of skimming does not regulate the minimum limit of criminal sanctions.
\end{abstract}




\section{Keyword: Accountability; Crime; Skimming}

Abstrak: Tujuan penelitian ini adalah untuk tindakan-tindakan yang dapat dilakukan untuk mencegah kejahatan pembobolan kartu ATM melalui skimming dan untuk menganalisis pertanggungjawaban pidana pelaku kejahatan pembobolan kartu ATM melalui skimming. Penelitian ini menggunakan beberapa pendekatan yakni pendekatan perundang-undangan (statute approach), pendekatan kasus (case approach), dan pendekatan konseptual (conceptual approach) dengan bahan hukum primer dan sekunder dengan teknis analisis preskriptif. Berdasarkan hasil penelitian bahwa 1) tindakan-tindakan yang dapat dilakukan untuk mencegah kejahatan pembobolan kartu ATM melalui skimming yaitu membangun pencegahan/pertahanan anti malware di seluruh server bank, keamanan jaringan, melindungi jaringan dari serangan, memonitor dan tes kontrol, membuat aplikasi unit untuk melaporkan setiap kejadian cybercrime khususnya mengenai skimming dan Meningkatkan kerja sama antar negara dalam upaya penanganan cybercrime khususnya mengenai skimming. 2) Pertanggungjawaban pidana atas pembobolan kartu ATM melalui skimming didasarkan pada terpenuhinya unsurunsur delik dan ancaman pidana terhadap pelaku tindak pidana skimming dapat dikenakan Pasal 30, Pasal 46, Pasal 32, Pasal 48 UU ITE mengingat adanya asas lex specialis derogate legi generali. Namun dalam penerapannya belum dapat diterapkan sendiri untuk menindak pelaku skimming, sehingga harus diterapkan bersamaan dengan hukum pidana konvensional yaitu Pasal 362 KUHP, Pasal 363 ayat (1) ke-4 jo. Pasal 263 jo. Pasal 55 ayat (1) ke-1 KUHP (penyertaan). Selain itu, tindak pidana skimming tidak mengatur tentang batas minimal sanksi pidana.

Kata kunci: Pertanggungjawaban; Tindak Pidana; Skimming

\section{PENDAHULUAN}

Pembobolan kartu ATM atau skimming masih menjadi hal yang diperhatikan. Pengertian daripada skimming itu sendiri merupakan pelaku kejahatan mengambil data dari pita magnetik yang ada di belakang kartu debit/kredit/ATM. bisa juga dikatakan skimming adalah teknik foto kopi data yang ada di kartu korban. ${ }^{1}$ Kegiatan skimming melalui internet menimbulkan kerugian pada para nasabah yang kehilangan saldo kreditnya tanpa menggunakan sama sekali. Para pelaku mencari dan melacak nomor kartu kredit melalui internet Linux untuk membuka dan mengambil uang nasabah dengan sistem transaksi online.

Kartu elektronik palsu ini dapat dibaca dan digunakan pada mesin ATM maupun mesin Debet layaknya kartu ATM. Pada akhir rangkaian proses tersebut maka pelaku skimming akan menggunakan kartu palsu yang ia buat menggunakan data nasabah untuk melakukan transaksi perbankan. Karena transaksi perbankan dilakukan pelaku dengan menggunakan jaringan

1 Mugiatno Sumbodo, Jafar Octo Fernas, "Skimming, Cara Kerja dan Pencegahan pada ATM", IKRA-ITH Teknologi, Vol 3, No. 2, 2019, hlm. 14. 
komputer yang aksesnya menggunakan data nasabah, maka sistem secara otomatis akan mengenali transaksi tersebut sebagai transaksi atas nama nasabah. ${ }^{2}$

Tidak ini terjadi di seluruh dunia termasuk Indonesia dan Sulawesi Tenggara di dalamnya. Nasabah yang memiliki masalah kartu kredit dibobol terjadi pada Bank Mandiri, BRI, BNI dan BCA. Keempat bank ini memiliki nasabah kartu kredit yang tersebar di seluruh Indonesia. Penangkapan terhadap para pelaku pembobol kartu kredit ini juga terjadi pada lokasi yang berbeda-beda. Para pelaku pembobol kartu kredit tidak memiliki domisili tetap dan untuk melacak keberadaan mereka, pihak kepolisian membutuhkan kerja sama dengan pihak perbankan yang menerbitkan kartu kredit tersebut.

Upaya penanggulangan untuk mengungkap kasus-kasus di bidang skimming, dilakukan dengan menggunakan peraturan perundang-undangan antara lain adalah KUHP dan UndangUndang Nomor 19 Tahun 2016 tentang Perubahan Atas Undang-Undang Nomor 11 Tahun 2008 tentang Informasi dan Transaksi Elektronik. Langkah ini diambil karena belum ada undangundang khusus yang mengatur tindak pidana yang berkaitan dengan hal tersebut. Kejahatan kartu kredit hanya diatur dalam pasal yang ada di dalam Undang-Undang Nomor 19 Tahun 2016 tentang Perubahan Atas Undang-Undang Nomor 11 Tahun 2008 tentang Informasi dan Transaksi Elektronik. Pasal-pasal yang digunakan untuk menjerat para pelaku sekaligus tersangka tindak pidana kejahatan kartu kredit (carding) yaitu Penipuan (Pasal 378 KUHP), Pemalsuan (Pasal 263 ayat (1) KUHP dan Pencurian 362 KUHP). ${ }^{3}$

Salah satu contoh kasus kejahatan pembobolan perbankan di Kota Kendari ialah dengan kejadian sejumlah dana nasabah Bank Negara Indonesia (BNI) Cabang Kendari, Sulawesi Tenggara (SULTRA), yang menjadi korban pembobolan saldo di rekening melalui Anjungan Tunai Mandiri (selanjutnya disebut ATM) ataupun mengalami kehilangan saldo atau terdebit menjadi 123 orang hingga Kamis 23 Januari 2021. Menurut Kepala Kantor Bank Nasional Indonesia (selanjutnya disebut BNI) Cabang Kendari, Muzakkir, menyebut dari 123 orang itu, tersisa sembilan orang yang belum dikembalikan uangnya. BNI akan mengganti uang nasabah yang hilang akibat skimming. Hingga saat ini, tercatat sudah Rp. 550 juta dikeluarkan bank untuk mengganti uang nasabah. ${ }^{4}$

2 Michael Enrick, "Pembobolan ATM Menggunakan Teknik Skimming Kaitannya dengan Pengajuan Restitusi", Jurist-Diction, Vol. 2, No. 2, 2019, hlm. 568.

3 Hendryawan Dwi Putra Idris, “Kebijakan dalam Penanggulangan Penyalahgunaan Kartu Kredit, Lex Privatum, Vol. VII, No. 4, 2019, hlm. 24.

4 "Nasabah BNI Kendari Korban Skimming Bertambah 123 Orang" CNN Indonesia, https://www.cnnindonesia.com/nasional/20200123184615-12-468145/nasabah-bni-kendari-korbanskimming-bertambah-123-orang, diakses pada tanggal 13 Juli 2021. 
Pelaku pembobolan ATM melalui modus skimmer dapat dijerat atau dikenakan Pasal 363 ayat (5) b Undang-Undang Hukum Pidana jo. Pasal 30 , Pasal 32 ayat (1) UU Nomor 11 Tahun 2008, tentang memindahkan informasi elektronik dan/atau dokumen elektronik milik orang lain atau milik publik, yang mana ketentuan pidananya diatur Pasal 48 ayat (1) dan Pasal 46 Undang-Undang Nomor 19 Tahun 2016 tentang Perubahan Atas Undang-Undang Nomor 11 Tahun 2008 tentang Informasi dan Transaksi Elektronik dengan ancaman hukuman penjara paling lama delapan tahun dan/atau denda paling banyak dua miliar rupiah.

Ketentuan Pasal 48 ayat (1) Undang-Undang Nomor 19 Tahun 2016 tentang Perubahan Atas Undang-Undang Nomor 11 Tahun 2008 tentang Informasi dan Transaksi Elektronik masih memiliki kelemahan, dimana ancaman minimal pidana tidak diatur sedangkan kejahatan skimming merupakan kejahatan yang memiliki dampak negatif terhadap sistem perekonomian dan kerugian yang ditimbulkan atas perbuatan tersebut cukup besar serta dapat menimbulkan ketakutan terhadap nasabah bank. Oleh karena itu, perlu diatur pidana minimal terhadap kejahatan skimming yang berdampak pada pertanggungjawaban pidana terhadap kejahatan skimming.

Upaya perlindungan hukum yang dikemukakan dalam berbagai undang-undang tersebut di atas selama ini masih dianggap remeh oleh para pelaku pembobolan kartu ATM dan sekaligus menunjukkan lemahnya pengamanan data nasabah kredit pada perbankan. Selain itu, upaya pencegahan perlu dilakukan sebab di dalam kejahatan perbankan pelaku pembobolan ATM memiliki kemampuan penguasaan sistem teknologi yang baik, sehingga bank harusnya memiliki langkah preventif yang lebih dinamis terhadap penguasaan teknologi dalam menanggulangi kejahatan tersebut.

Kejahatan skimming yang terjadi di Bank BNI dan BCA di Kota Kendari belum ada putusan pengadilan atas kejahatan tersebut. Dengan demikian maka untuk menilai pertanggungjawaban pidana atas kejahatan skimming maka dilakukan kajian hukum pertanggungjawaban pidana atas Putusan Pengadilan Nomor 1045/Pid.B/2020/PN.JKT.TIM yang terjadi di Jakarta Timur dimana pelaku kejahatan skimming melanggar ketentuan dalam Pasal 363 ayat (1) ke-4 KUHP jo. Pasal dan Pasal 46 UU ITE. Terdakwa dalam kejahatan skimming ini dilakukan oleh warga negara asing dimana pidana yang dijatuhkan hanya 2 tahun penjara dengan total kerugian nasabah Rp. 19.000.000,- (sembilan belas juta rupiah) yang terjadi di 2 bank yaitu Bank Mandiri dan Bank CIMB Niaga. 


\section{METODE PENELITIAN}

Tipe penelitian ini menggunakan tipe penelitian hukum. Dengan demikian penelitian ini mencakup analisis hukum tertulis yang didahului inventarisasi hukum positif. Hal ini akan menjadi salah satu produk analisa abstraksi dari norma hukum positif. ${ }^{5}$ Metode pendekatan yang digunakan dalam penelitian ini adalah Pendekatan perundang-undangan (statute approach), pendekatan kasus dan pendekatan konseptual (conseptual approach) dengan bahan hukum primer dan sekunder dengan teknis analisis preskriptif.

\section{ANALISIS DAN PEMBAHASAN}

\section{Tindakan-tindakan yang Dapat Dilakukan untuk Mencegah Kejahatan Pembobolan}

\section{Kartu ATM Melalui Skimming}

Peran teknologi dalam dunia perbankan sangat mutlak, dimana kemajuan suatu sistem perbankan sudah barang tentu ditopang oleh peran teknologi informasi.6 Tidak dapat dipungkiri, dalam setiap bidang termasuk perbankan penerapan teknologi adalah untuk memudahkan operasional intern perusahaan, juga bertujuan untuk semakin memudahkan pelayanan terhadap nasabah. ${ }^{7}$ Apalagi saat ini, khususnya dalam dunia perbankan hampir semua produk yang ditawarkan kepada nasabah serupa, sehingga persaingan yang terjadi dalam dunia perbankan adalah bagaimana memberikan produk yang serba mudah, cepat dan praktis. $^{8}$

Seiring dengan perkembangan teknologi, masyarakat memang diberi kemudahan dalam setiap proses transaksi keuangan. Adanya fasilitas transaksi perbankan dengan sistem elektronik seperti kartu ATM (anjungan tunai mandiri), fasilitas internet banking, fasilitas mobile banking, fasilitas kartu kredit, dan berbagai fasilitas-fasilitas lainnya membuat masyarakat semakin nyaman dan mudah untuk menyimpan dan mengambil uang mereka di bank. Sejak

5 Soentandyo Wingyosoebroto, Penelitian Hukum, Surabaya, Surabaya: Pusat Studi Hukum dan Pembangunan Fakultas Hukum Unair, 1974, hlm 1,7-8

6 Sony Andes, "Pencegahan Kejahatan Skimming Perbankan", Petrominer, https://petrominer.com/ pencegahan-kejahatan-skimming-perbankan/, diakses pada tanggal 28 Mei 2021.

7 Eko Wijaksono, Kiki Farida, Inge Salman, Irma Herdiani, "Analisator IT", Makalah, Program Studi Komputerisasi Akuntansi Fakultas Teknik dan Ilmu Komputer, Bandung: Universitas Komputer Indonesia, 2014, hlm. 2.

8 Anggi Olivia Sitorus, "Pemanfaatan Teknologi Informasi Pada Bagian Pelayanan Nasabah di PT. Bank Tabungan Pensiun Nasional (BTPN) Tbk. Cabang Putri Hijau", Tugas Akhir, Program Studi Diploma III Kesekretariatan Fakultas Ekonomi dan Bisnis, Medan: Universitas Sumatera Utara, 2020, hlm. 3. 
diperkenalkannya fasilitas elektronik ini, maka kegiatan transaksi perbankan berlangsung begitu cepat dan tidak lagi mengenal batasan waktu dan tempat. ${ }^{9}$

Namun, kadang kala secanggih apa pun sebuah teknologi, tetap saja bisa dilabrak juga oleh orang-orang yang mau berniat jahat seperti kasus pembobolan bank akhir-akhir ini. Banyak faktor yang bisa membuat seseorang memiliki kesempatan untuk melakukan pembobolan dana tabungan milik orang lain. Sebagian besar pelaku pembobolan rekening nasabah suatu bank menurut saya adalah oknum pegawai bank itu sendiri, karena mereka tahu seluk beluk mengenai kegiatan transaksi perbankan. Pelakunya bisa saja mantan pegawai bank atau orang di luar pegawai bank yang memang memiliki keahlian dalam bidang IT yang khusus mengutak-atik kode akses perbankan. ${ }^{10}$

Perbankan adalah suatu lembaga keuangan yang sangat rawan kejahatan. Pembobolan, perampokan, pemalsuan kartu kredit dan tanda tangan, dan bahkan penyelewengan dana nasabah oleh oknum pegawai bank sudah menjadi catatan sejarah buruk suatu bank. Namun, tidak bisa menyalahkan satu pihak saja. ${ }^{11}$

Ditinjau dari aspek hukum pidana, maka perbuatan pembobolan rekening perbankan dapat dijerat dengan ketentuan Pasal 30 Undang-undang Nomor 11 Tahun 2008 tentang Informasi dan Transaksi Elektronik yang berbunyi:

(1) Setiap orang dengan sengaja dan tanpa hak atau melawan hukum mengakses komputer dan/atau sistem elektronik milik orang lain dengan cara apa pun.

(2) Setiap orang dengan sengaja dan tanpa hak atau melawan hukum mengakses komputer dan/atau sistem elektronik dengan cara apa pun dengan tujuan untuk memperoleh Informasi Elektronik dan/atau Dokumen Elektronik.

(3) Setiap orang dengan sengaja dan tanpa hak atau melawan hukum mengakses komputer dan/atau sistem elektronik dengan cara apa pun dengan melanggar, menerobos, melampaui, atau menjebol sistem pengamanan. ${ }^{12}$

Alternatif tindakan pencegahan untuk menghindari terjadinya kejahatan kartu ATM adalah sebagai berikut: 13

9 "BLBI dan Korupsi Perbankan Masa Kini", Seminar Anti-Korupsi GEMPAR (Gerakan Muda Penggiat AntiKorupsi Paramadina, Jakarta: Universitas Paramadina, 2011, hlm. 2.

10 Ibid.

11 Ibid.

12 Sutan Remy Syahdeini, Kejahatan \& Tindak Pidana Komputer, Jakarta: PT. Pustaka Utama Grafiti, 2009, hlm. 240.

13 Ahmad Reza Wildan, "Money Laundering dan Modus Kejahatan Produk Perbankan", Academia.edu, https://www.academia.edu/9869654/Money_Laundering_dan_Modus_Kejahatan_Produk_Perbankan, diakses pada tanggal 19 Mei 2021, hlm. 12. 
1. Pihak Perbankan dalam sistem kartu ATM agar segera memanfaatkan Card Verification Value (CVV) supaya bisa mempersulit upaya-upaya pemalsuan kartu ATM.

2. Pihak Perbankan sebaiknya menambah security camera di setiap sudut di lokasi mesin ATM atau di ATM Center baik di Mal maupun di bank dan tempat-tempat mesin ATM ada, agar dapat merekam semua segala aktivitas orang-orang yang melakukan transaksi di ATM atau aktivitas lainnya.

3. Nasabah sebaiknya selalu menyimpan nomor pengaduan yang diberikan oleh bank untuk di simpan di handphone nasabah, nasabah bisa menanyakan langsung pada customer service bank.

4. Pengawasan dilingkungan perbankan harus semakin di perketat.

5. Hindari alat-alat yang seharusnya tidak ada di ATM biasa seperti:

a. Magnetic Card Rider berfungsi untuk membaca data kartu magnetik ATM yang dipakai untuk menggandakan (kloning) kartu ATM. terbuat dari gipsum, warnanya mirip dengan warna ATM. Skimmer umumnya ditempel dengan double tape sehingga mudah lepas saat digoyang, dipasang di tempat untuk memasukkan kartu.

b. Kamera kecil (spycamera/mini camera) biasanya dipasang di badan ATM atau di-sernya, ukurannya tipis dan memanjang sehingga bisa ditempel di atas atau samping tombol untuk mengetik PIN. Intinya semua yang mengarah ke tombol untuk mengetik PIN harus diwaspadai.

Mengingat semakin banyak kasus-kasus yang terindikasi sebagai cyber crime, maka selain aspek hukum maka secara teknis juga perlu disiapkan berbagai upaya preventif terhadap penanggulangan kasus cyber crime. Oleh sebab itu, nasabah harus lebih berhati-hati dalam melakukan transaksi melalui ATM ataupun melalui internet. Untuk menghindari pembobolan ATM dengan cara skimming ada beberapa cara untuk menghindarinya: ${ }^{14}$

a. Periksa di sekeliling ATM bahwa tidak ada benda yang mencurigakan, seperti kamera tersembunyi.

b. Cek apakah mesin ATM berfungsi normal (tombol bekerja dengan baik dan kartu mudah dimasukkan).

14 Bucimuchal Pujakemi, “Cara Jenius Cegah Kejahatan Skimming”, Jenius, https://www.jenius.com/ highlight/detail/cara-jenius-cegah-kejahatan-skimming, diakses pada tanggal 17 Mei 2021. 
c. Pada saat bertransaksi menggunakan kartu ATM pada merchant (toko yang bekerja sama dengan pihak perbankan), diharapkan nasabah memperhatikan kondisi alat EDC, bila terdapat alat (device) mencurigakan yang menempel pada EDC atau hal lain yang mencurigakan, nasabah dihimbau tidak bertransaksi dan segera melaporkan kepada pihak bank terdekat atau kepada pihak berwajib.

d. Segera blokir kartu ATM bila menemukan kejanggalan transaksi.

e. Cari lokasi ATM yang relatif aman.

f. Jangan mudah percaya dengan bantuan orang lain di ATM.

Usaha melaksanakan tindakan pencegahan dari berbagai pihak dianggap turut memegang peranan penting agar hasil dan tujuan diharapkan dapat tercapai baik secara langsung maupun tidak langsung dan turut bertanggung Jawab dalam usaha pencegahan kejahatan pembobolan ATM melalui skimming adalah pihak kepolisian dan pihak bank. Adapun wujud usaha pencegahan dari masing-masing mengenai tindakan-tindakan yang dapat dilakukan untuk mencegah kejahatan pembobolan kartu ATM melalui skimming dapat dijelaskan sebagai berikut: ${ }^{15}$

1. Memberikan pengetahuan dan kesadaran penggunaan internet dengan baik, dan mencegah risiko/dampak kejahatan akan dunia maya kepada masyarakat khususnya mengenai kejahatan skimming.

2. Mengoptimalkan undang-undang khusus lainnya.

3. Membangun pencegahan/pertahanan anti malware di seluruh server bank.

4. Keamanan jaringan, melindungi jaringan dari serangan, memonitor dan tes kontrol.

5. Pengontrolan terhadap keluar masuknya akses yang tidak sah dan konten berbahaya.

6. Melakukan modernisasi hukum pidana nasional beserta hukum acaranya.

7. Meningkatkan kerja sama antar negara dalam upaya penanganan cybercrime khususnya mengenai skimming.

8. Membuat aplikasi unit untuk melaporkan setiap kejadian cybercrime khususnya mengenai skimming.

\section{Pertanggungjawaban Pidana Pelaku Kejahatan Skimming Kartu ATM}

Perbuatan skimming merupakan salah satu kegiatan yang bersifat negatif dan merugikan banyak pihak dengan mengambil atau menyalin data elektronik secara melawan hukum dan

\footnotetext{
15 Sony Andes, $O p$, cit.
} 
tanpa hak terhadap suatu sistem komputer. Perbuatan skimming digunakan untuk kepentingan pribadi yang sifatnya merugikan, dan perbuatan tersebut mengakibatkan kerugian material maupun imateriel yang cenderung lebih besar dibandingkan dengan kejahatan konvensional. Kecanggihan teknik skimming saat ini adalah langsung menyalin data yang didapat dari skimmer secara online, menggunakan remote, teknologi GSM, ataupun Bluetooth. Jadi teknik tersebut memungkinkan pelaku untuk mengirimkan data yang didapat dari skimmer ke komputer atau smartphone yang dipasang di lokasi tertentu, sehingga pelaku skimming dapat mengakses data di mana pun. 16

Pelaku skimming juga dapat dikenai dengan Pasal 263 KUHP yang mengandung unsur objektif dan unsur subjektif. Unsur objektif merupakan perbuatan memalsu surat yang dianggap adanya kehendak untuk memalsukannya, dikatakan telah memalsukan surat apabila surat yang sudah ada dengan cara menghapus, mengubah, atau mengganti salah satu isinya sehingga berbeda dengan surat aslinya. Apabila diterapkan dalam tindak pidana skimming, maka dapat diartikan bahwa perbuatan memasukkan data atau informasi elektronik ke dalam kartu kosong/bodong milik pelaku, kemudian dipergunakan layaknya kartu ATM aslinya dan menimbulkan kerugian terhadap nasabah termasuk dalam unsur perbuatan memalsukan surat berupa kartu ATM. Unsur subjektif dalam Pasal 263 ayat (1) KUHP adalah unsur dengan maksud bahwa pelaku skimming telah menghendaki perbuatan yang dilakukan untuk memalsukan surat berupa kartu ATM karena termasuk dalam surat yang dapat menimbulkan hak, suatu perikatan, dan dapat menimbulkan kerugian akibat dari penggunaannya oleh pelaku. Sedangkan dalam Pasal 263 ayat (2) unsur sengaja mempergunakan surat palsu ditujukan kepada orang yang menggunakan itu harus benar-benar mengetahui bahwa surat tersebut palsu. Sehingga perlu dibuktikannya penggunaan kartu ATM tersebut seolah-olah surat itu asli dan tidak dipalsukan, dan atas perbuatannya itu menimbulkan adanya kerugian. ${ }^{17}$

Dalam UU ITE kata dasar dari mengakses adalah akses yang tafsir otentiknya dalam Pasal 1 angka 15 UU ITE adalah kegiatan melakukan interaksi dengan system elektronik yang berdiri sendiri atau jaringan. Bahwa sifat dilarangnya perbuatan mengakses komputer dan/atau sistem elektronik untuk memperoleh informasi elektronik, karena sistem elektronik

\footnotetext{
16 Destya Fidela, "Pertanggungjawaban Tindak Pidana Skimming”, Jurist-Diction, Vol. 2, No. 4, 2019, hlm. 1226.

17 Ibid., hlm. 1227.
} 
tersebut milik orang lain dan tidak ada ijin dari yang bersangkutan. ${ }^{18}$ Tujuan pelaku mengakses yaitu berusaha memperoleh data elektronik yang ada pada kartu debit/kredit milik nasabah yang nantinya akan digunakan sebagai informasi dan dipergunakan sebagaimana dimaksud dalam Pasal 32 ayat (1) dan ayat (2). Unsur setiap orang dalam Pasal 30 dan Pasal 32 merujuk pada pelaku yang bertanggungjawab. Pengertian dari pelaku menurut Zainal Abidin adalah seorang yang memenuhi unsur-unsur delik, baik yang dinyatakan secara ecpress verbis maupun yang diterima secara diam-diam (stilzwiiigende element) atau yang berkewajiban untuk mengakhiri keadaan yang dilarang oleh undang- undang pidana, baik yang dinyatakan secara tegas di dalam undang-undang pidana maupun yang diterima secara diam-diam. ${ }^{19}$

Cara yang dilakukan oleh pelaku dengan menggunakan alat skimmer untuk menyalin data elektronik pada kartu termasuk dalam unsur Pasal 30 ayat (3) karena telah berusaha menerobos sistem pengaman pada mesin ATM. Ketentuan berdasarkan Pasal 30 maupun Pasal 32 mengandung makna hukum, bahwa data atau informasi yang merupakan hasil mengakses tersebut diberikan kepada yang berhak, maka tidak dapat dituntut pertanggungjawaban pidananya sebab tidak dikualifikasi sebagai delik, walaupun data atau informasi yang diakses itu milik orang lain. Perhatikan makna kata dalam Pasal 32 ayat (1) khusus mengenai cara "mengubah, menambah, mengurangi, melakukan transmisi, merusak, menghilangkan, memindahkan, menyembunyikan suatu informasi elektronik dan/atau dokumen elektronik....".

Menurut penulis perlu dipahami bahwa unsur-unsur yang ada dalam pasal tersebut adalah alternatif, sehingga dapat dibuktikan salah satu unsur atau sebagian atau seluruh unsur. Jika dikaitkan dengan tindak pidana skimming maka cara yang digunakan yaitu melakukan transmisi, dan memindahkan. Sedangkan dalam Pasal 32 ayat (2) menggunakan makna memindahkan atau mentransfer informasi elektronik dan/atau dokumen elektronik, Penjelasan dalam Pasal 32 telah mengatakan cukup jelas, sedangkan Lembaga pertanggungjawaban pidana mengajarkan harus jelas dan pelaku delik memahami tuduhan yang diajukan kepada dirinya.

Berdasarkan putusan Nomor 1045/Pid.B/2020/PN.JKT.TIM atas nama terdakwa Hayrullah Cyellan sebagai terdakwa I, terdakwa Ufuk Kemanici sebagai terdakwa II, Hakkan Battal sebagai terdakwa III bahwa kejahatan ini dilakukan di 2 bank yakni Bank Mandiri dan

18 Adami Chazawi dan Ardi Ferdian, Tindak Pidana Informasi dan Transaksi Elektronik 'Penyerangan Terhadap Kepentingan Hukum Pemanfaatan Teknologi Informasi dan Transaksi Elektronik', Jakarta: Media Nusa Creative, 2015. hlm. 144.

19 Zainal Abidin dan Hamzah, Bentuk-bentuk Khusus Perwujudan Delik dan Hukum Penitensier, Jakarta: PT. RajaGrafindo Persada, 2006. hlm. 178. 
CIMB Niaga, total kerugian di Bank Mandiri mencapai Rp. 11.000.000,- (sebelas juta rupiah) dan di Bank CIMB Niaga sebesar Rp. 8.000.000,- (delapan juta rupiah). Berdasarkan putusan pengadilan Nomor 1045/Pid.B/2020/PN.JKT.TIM terdakwa melakukan kejahatan yang terdapat dalam ketentuan Pasal 30 dan Pasal 46 Undang-undang Nomor 19 Tahun 2016 tentang Perubahan atas Undang-undang Nomor 11 Tahun 2008 tentang Informasi dan Transaksi Elektronik jo. Pasal 363 ayat (1) ke-4 KUHP. Dalam putusan pengadilan Nomor 1045/Pid.B/2020/PN.JKT.TIM Jaksa Penuntut Umum tidak mendakwakan Pasal 30 dan 46 Undang-undang Nomor 19 Tahun 2016 tentang Perubahan atas Undang-undang Nomor 11 Tahun 2008 tentang Informasi dan Transaksi Elektronik, namun akan dipertimbangkan hakim dalam putusannya sebagai keadaan-keadaan yang memberatkan.

Putusan Pengadilan Nomor 1045/Pid.B/2020/PN.JKT.TIM tentang kejahatan skimming menjatuhkan pidana 2 tahun penjara terhadap terdakwa I, terdakwa II, dan terdakwa III. Penjatuhan pidana 2 tahun penjara bukanlah permasalahan hukum sebab ketentuan Pasal 363 ayat (1) ke-4 KUHP ancaman pidana maksimal 9 tahun dan tidak menyebutkan batas minimal begitu pula di dalam Pasal 46 UU ITE yang ancaman pidananya maksimal 5 tahun.

Menurut penulis dalam penegakan hukum pidana khususnya kejahatan skimming perlu dimuat rumusan batas minimal ancaman pidana bagi pelaku kejahatan skimming di dalam UU ITE. Selain itu, dalam Putusan Pengadilan Nomor 1045/Pid.B/2020/PN.JKT.TIM tidak merumuskan pasal 46 sebagai ancaman pidananya bagi pelaku kejahatan skimming oleh Jaksa Penuntut Umum, sebab Jaksa Penuntut Umum menilai ancaman pidana kejahatan skimming lebih tinggi yang diatur dalam Pasal 363 ayat (1) ke-4 KUHP jika dibandingkan dengan Pasal 46 UU ITE yang ancaman pidananya 5 tahun penjara. Selain itu, meskipun ancaman pidana terhadap pelaku skimming dalam UU ITE lebih rendah seharusnya Jaksa Penuntut Umum tetap merumuskan Pasal 30 dan Pasal 46 UU ITE di dalam surat dakwaannya, agar pertanggungjawaban pidana dalam kejahatan skimming dapat dirumuskan secara jelas. Selain itu Putusan Pengadilan Nomor 1045/Pid.B/2020/PN.JKT.TIM dapat menjatuhkan pidana lebih berat sebab dilakukan oleh warga negara asing sebagai dasar pemberatan dalam pertanggungjawaban pidana namun hal tersebut tidak diuraikan di dalam putusan pengadilan tersebut.

\section{KESIMPULAN}

Tindakan-tindakan yang dapat dilakukan untuk mencegah kejahatan pembobolan kartu ATM melalui skimming yaitu membangun pencegahan/pertahanan anti malware di seluruh server 
bank, keamanan jaringan, melindungi jaringan dari serangan, memonitor dan tes kontrol, membuat aplikasi unit untuk melaporkan setiap kejadian cybercrime khususnya mengenai skimming dan Meningkatkan kerja sama antar negara dalam upaya penanganan cybercrime khususnya mengenai skimming. Pertanggungjawaban pidana atas pembobolan kartu ATM melalui skimming didasarkan pada terpenuhinya unsur-unsur delik dan ancaman pidana terhadap pelaku tindak pidana skimming dapat dikenakan Pasal 30, Pasal 46, Pasal 32, Pasal 48 UU ITE mengingat adanya asas lex specialis derogate legi generali. Namun dalam penerapannya belum dapat diterapkan sendiri untuk menindak pelaku skimming, sehingga harus diterapkan bersamaan dengan hukum pidana konvensional yaitu Pasal 362 KUHP, Pasal 363 ayat (1) ke-4 jo. Pasal 263 jo. Pasal 55 ayat (1) ke-1 KUHP (penyertaan). Selain itu, tindak pidana skimming tidak mengatur tentang batas minimal sanksi pidana.

\section{Daftar Pustaka}

Buku

Abidin, Zainal dan Hamzah, Bentuk-bentuk Khusus Perwujudan Delik dan Hukum Penitensier, Jakarta: PT. RajaGrafindo Persada, 2006.

Chazawi, Adami dan Ardi Ferdian, Tindak Pidana Informasi dan Transaksi Elektronik 'Penyerangan Terhadap Kepentingan Hukum Pemanfaatan Teknologi Informasi dan Transaksi Elektronik', Jakarta: Media Nusa Creative, 2015.

Syahdeini, Sutan Remy, Kejahatan \& Tindak Pidana Komputer, Jakarta: PT. Pustaka Utama Grafiti, 2009.

Wijaksono, Eko, Kiki Farida, Inge Salman, Irma Herdiani, “Analisator IT”, Makalah, Program Studi

Komputerisasi Akuntansi Fakultas Teknik dan Ilmu Komputer, Bandung: Universitas Komputer Indonesia, 2014.

Wingyosoebroto, Soentandyo, Penelitian Hukum, Surabaya, Surabaya: Pusat Studi Hukum dan Pembangunan Fakultas Hukum Unair, 1974.

\section{Jurnal dan Makalah}

Enrick, Michael, "Pembobolan ATM Menggunakan Teknik Skimming Kaitannya dengan Pengajuan Restitusi", Jurist-Diction, Vol. 2, No. 2, 2019.

Fidela, Destya, “Pertanggungjawaban Tindak Pidana Skimming”, Jurist-Diction, Vol. 2, No. 4, 2019. 
Idris, Hendryawan Dwi Putra, "Kebijakan dalam Penanggulangan Penyalahgunaan Kartu Kredit, Lex Privatum, Vol. VII, No. 4, 2019.

Sitorus, Anggi Olivia, "Pemanfaatan Teknologi Informasi Pada Bagian Pelayanan Nasabah di PT. Bank Tabungan Pensiun Nasional (BTPN) Tbk. Cabang Putri Hijau", Tugas Akhir, Program Studi Diploma III Kesekretariatan Fakultas Ekonomi dan Bisnis, Medan: Universitas Sumatera Utara, 2020.

Sumbodo, Mugiatno, Jafar Octo Fernas, "Skimming, Cara Kerja dan Pencegahan pada ATM", IKRA-ITH Teknologi, Vol 3, No. 2, 2019.

\section{Peraturan Perundang-undangan}

Undang-undang Nomor 1 Tahun 1946 tentang Kitab Undang-undang Hukum Pidana

Undang-undang No. 7 Tahun 1992 sebagaimana telah diubah dengan Undang-undang No. 10 Tahun 1998 tentang Perbankan.

Undang-Undang Republik Indonesia Nomor 3 Tahun 2004 tentang Bank Indonesia Lembaran Negara Republik Indonesia Tahun 2004 Nomor 7.

Undang-Undang Nomor 19 Tahun 2016 perubahan atas Undang-Undang Nomor 11 Tahun 2008 tentang Informatika dan Transaksi Elektronik

Peraturan Pemerintah Nomor 82 Tahun 2012 tentang Penyelenggaraan Sistem dan Transaksi Elektronik.

Peraturan Bank Indonesia Nomor 14/2/PBI/2012 tentang perubahan atas Peraturan Bank Indonesia Nomor 11/11/PBI/2009 tentang Penyelenggaraan Kegiatan Alat Pembayaran Dengan Menggunakan Kartu.

\section{Situs Web}

"Nasabah BNI Kendari Korban Skimming Bertambah 123 Orang" CNN Indonesia, https://www.cnnindonesia.com/nasional/20200123184615-12-468145/nasabahbni-kendari-korban-skimming-bertambah-123-orang, diakses pada tanggal 13 Juli 2021.

"BLBI dan Korupsi Perbankan Masa Kini”, Seminar Anti-Korupsi GEMPAR (Gerakan Muda Penggiat Anti-Korupsi Paramadina, Jakarta: Universitas Paramadina, 2011.

Andes, Sony, "Pencegahan Kejahatan Skimming Perbankan", Petrominer, https://petrominer.com/pencegahan-kejahatan-skimming-perbankan/, diakses pada tanggal 28 Mei 2021. 
Pujakemi, Bucimuchal, "Cara Jenius Cegah Kejahatan Skimming”, Jenius, https://www.jenius.com/highlight/detail/cara-jenius-cegah-kejahatan-skimming, diakses pada tanggal 17 Mei 2021.

Wildan, Ahmad Reza, "Money Laundering dan Modus Kejahatan Produk Perbankan", Academia.edu, https://www.academia.edu/9869654/Money_Laundering_dan_ Modus_Kejahatan_Produk_Perbankan, diakses pada tanggal 19 Mei 2021. 